\title{
Short communication: In vitro rumen gas production and starch degradation of starch-based feeds depend on mean particle size
}

\author{
A. Gallo, ${ }^{* 1}$ G. Giuberti, ${ }^{*}$ A. S. Atzori, $\dagger$ and F. Masoero* \\ *Department of Animal Science, Food and Nutrition (DIANA), Facoltà di Scienze Agrarie, Alimentari e Ambientali, \\ Università Cattolica del Sacro Cuore, 29100 Piacenza, Italy \\ †Dipartimento di Agraria, Sezione di Scienze Zootecniche, Università di Sassari, 07100 Sassari, Italy
}

\begin{abstract}
Our objective was to model the effect of mean particle size (mPS) on in vitro rumen starch degradation (IVSD) and the kinetics of gas production for different starch-based feeds. For each feed, 2 batches of the same grains were separately processed through 2 different mills (cutter or rotor speed mills), with or without different screens to achieve a wide range of mPS (0.32 to $3.31 \mathrm{~mm}$ for corn meals; 0.19 to $2.81 \mathrm{~mm}$ for barley meals; 0.16 to $2.13 \mathrm{~mm}$ for wheat meals; 0.28 to 2.32 $\mathrm{mm}$ for oat meals; 0.21 to $2.36 \mathrm{~mm}$ for rye meals; 0.40 to 1.79 for sorghum meals; 0.26 to $4.71 \mathrm{~mm}$ for pea meals; and 0.25 to $4.53 \mathrm{~mm}$ for faba meals). The IVSD data and gas production kinetics, obtained by fitting to a single-pool exponential model, were analyzed using a completely randomized design, in which the main tested effect was mPS $(n=6$ for all tested meals, except $\mathrm{n}=7$ for corn meals and $\mathrm{n}=5$ for sorghum meals). Rumen inocula were collected from 2 fistulated Holstein dairy cows that were fed a total mixed ration consisting of $16.2 \%$ crude protein, $28.5 \%$ starch, and $35.0 \%$ neutral detergent fiber on a dry matter basis. The IVSD, evaluated after $7 \mathrm{~h}$ of rumen incubation, decreased linearly with increasing mPS for corn, barley, wheat, rye, pea, and faba meals, and decreased quadratically with increasing mPS for the other meals. The $\mathrm{y}$-axis intercept for 7-h IVSD was below $90 \%$ starch for corn, barley, and rye feeds and greater than $90 \%$ for the other tested feeds. The mPS adjustment factors for the rate of rumen starch degradation varied widely among the different tested feeds. We found a linear decrease in starch degradation with increasing mPS for barley, wheat, rye, and pea meals, whereas we noted a quadratic decrease in starch degradation for the other tested meals. Further, we observed a linear decrease in the rate of gas production with increasing $\mathrm{mPS}$ in each
\end{abstract}

Received October 5, 2017.

Accepted March 14, 2018.

${ }^{1}$ Corresponding author: antonio.gallo@unicatt.it tested feed, except for pea meal, which had a quadratic relationship. For each $1 \mathrm{~mm}$ increase in $\mathrm{mPS}$, the gas production was adjusted by $-0.009 \mathrm{~h}^{-1}$ for corn, -0.011 $\mathrm{h}^{-1}$ for barley, $-0.008 \mathrm{~h}^{-1}$ for wheat, and $-0.006 \mathrm{~h}^{-1}$ for faba, whereas numerically greater adjustments were needed for oat $\left(-0.022 \mathrm{~h}^{-1}\right)$, rye $\left(-0.017 \mathrm{~h}^{-1}\right)$, and sorghum $\left(-0.014 \mathrm{~h}^{-1}\right)$. These mPS adjustment factors could be used to modify the starch-based feed energy values as a function of mean particle size, although in vivo validation is required.

Key words: in vitro method, processing, fermentation kinetics, nutritional model

\section{Short Communication}

Farmers typically give high-energy diets to lactating dairy cows. However, diets that are rapidly fermented in the rumen can lead to the rapid production of VFA. If the production of these acids exceeds the ability of the rumen to neutralize and absorb them, SARA can occur, thus worsening microbial fermentation, rumen epithelial function, animal health, and milk production (Silveira et al., 2007; Penner et al., 2009). Therefore, many developers of ruminant nutrition models have recently focused on prediction of starch digestion dynamics in the digestive tracts of dairy cows (Higgs et al., 2015; Bannink et al., 2016; Ghimire et al., 2017). Two recent meta-analyses (Patton et al., 2012; Moharrery et al., 2014) aimed to determine the amount of starch digested in the different compartments of the gastrointestinal tract and to identify the main factors affecting starch digestion dynamics. In both cases, the proposed starch digestion submodels were mainly based on starch sources and starch intake levels. Nonetheless, it was difficult to include certain other factors in these models. Thus, Patton et al. (2012) declared "... inaccuracies in prediction of starch degradability in the rumen may be mainly due to processing effects and particle sizes, but these were not well reported in literature and were difficult to estimate," and Moharrery et al. (2014) stated "... effects of physical structure and heat treatment were initially tested, however data balance 
did not allow for conclusive statements for the present dataset and approach."

Previous studies suggested that the mean particle size (MPS) of feeds can affect digestion rate (Hoffman et al., 2012; Zhao et al., 2015; Tagawa et al., 2017), and that differences in the passage rates of large, medium, and small particles exist within the different gastrointestinal compartments of ruminant animals (Nocek and Tamminga, 1991; Offner and Sauvant, 2004; Ferraretto et al., 2013). We previously modeled the effects of mPS on in vitro rumen starch degradation (IVSD) and OM fermentability (Gallo et al., 2016) by examination of a wide range of mPS, with meals consisting of dry wholekernel corn ( $\mathrm{n}=11 \mathrm{mPS}, 0.46$ to $3.50 \mathrm{~mm}$ ) and dry hulless whole-kernel barley $(\mathrm{n}=10 \mathrm{mPS}, 0.11$ to 2.98 $\mathrm{mm}$ ), by use of well-established rumen-based in vitro methods. We proposed the use of mPS adjustment factors (i.e., the slopes of regression terms in which mPS represented the independent variable) to characterize the rate of rumen starch degradation (kd starch) and the amount of starch degradation after $7 \mathrm{~h}$ of in vitro rumen incubation (7hIVSD). In particular, the previous study indicated that for each $1-\mathrm{mm}$ increase in mPS, corn feed had a linear decrease of $0.049 \mathrm{~h}^{-1}$ in the kd starch and a 6.3 percentage units decrease in the 7hIVSD, and barley feed had a linear decrease of 0.092 $\mathrm{h}^{-1}$ in the kd starch and a 6.5 percentage units decrease in the $7 \mathrm{hIVSD}$.

The purpose of the current study was to extend the previous approach to other starch-based feeds, with the aim to model the effect of mPS on IVSD data and the kinetics of gas production. In particular, we selected the same raw starch-based feeds examined in the previous meta-analysis of Moharrery et al. (2014).

Two 5-kg batches of dry whole corn, dry hulled barley, dry wheat, dry oat, dry rye, and dry sorghum kernels were collected over 2 wk ( 1 batch each week) from the same feedstock grains stored in grain storage bins at local industrial feed mills. Two batches of dry whole pea (Pisum sativum) and faba (Vicia faba var. minor) beans were generously donated by the Centro Ricerche Produzioni Animali S.p.A. (CRPA, Reggio Emilia, Italy).

To obtain different mPS, subsamples of about 1.3 to $1.5 \mathrm{~kg}$ for each batch were processed as described by Hoffman et al. (2012), in which a cutter mill (Pulviresette 19, Fritsch, Idar-Oberstein, Germany) that was fitted with 4.0-, 3.0-, 2.0-, or 1.0-mm screens (1 passage) or without screens (1 to 5 passages) was used. Samples were also passed through a rotor speed mill Pulverisette 14 (Fritsch) that was equipped with 1.0and $0.5-\mathrm{mm}$ screens (1 passage; Table 1). Afterward, a representative amount $(100 \mathrm{~g})$ of the various grinds was run for 10 min through a sieve shaker (Multidimensional
Sieveshaker IG/1/S, Giuliani Tecnologie s.r.l., Torino, Italy) that had 9 different screen sieves with nominal aperture sizes of $4.00,3.50,2.50,1.50,1.00,0.75,0.50$, 0.25 , and $0.125 \mathrm{~mm}$, followed by a pan. The mPS was measured using equation 1 of ASAE S319.3 method, as reported in ASABE (2006). In particular, the mPS of each material retained on a sieve was calculated on a weight basis as the geometric mean of the diameter of the openings in the 2 adjacent sieves in the stack (Pfost and Headley, 1976). A portion of each subsample that was ground through a screen of over $0.50 \mathrm{~mm}$ was reground by the rotor speed mill equipped with $0.50-\mathrm{mm}$ screen and analyzed for total starch (Megazyme assay kit K-TSTA 07/11), ash (AOAC International, 2000; method 942.05), and CP (AOAC International, 2000; method 984.13).

The IVSD was evaluated by an in vitro rumen-based method, which was slightly modified from the method of Sveinbjörnsson et al. (2007). Rumen fluid was collected from 2 fistulated dairy cows that received a TMR (16.2\% CP, $28.5 \%$ starch, and $35.0 \%$ NDF on a DM basis), formulated according to the NRC (2001) for an average BW of $600 \mathrm{~kg}, 140$ DIM, and $35 \mathrm{~kg}$ of milk yield (3.75\% fat and $3.35 \%$ protein). The diet consisted of corn silage, energy-protein supplement, alfalfa, and grass hays $(31.2,48.0,16.7$, and $4.1 \% \mathrm{DM}$, respectively). Rumen liquor was maintained in a warm insulated flask, filtered through 2 layers of cheesecloth, and used within 20 min of collection. Samples containing $250 \mathrm{mg}$ of starch were weighed in $125-\mathrm{mL}$ glass bottles (Wheaton borosilicate glass serum bottle; 54 $\mathrm{mm}$ diameter $\times 107 \mathrm{~mm}$ height; Z114014; Sigma-Aldrich Co., Milan, Italy), which were filled with $30 \mathrm{~mL}$ of the diluted rumen fluid (buffer-to-rumen ratio 2:1, $\mathrm{vol} / \mathrm{vol}$ ), gassed with $\mathrm{CO}_{2}$, closed with rubber stoppers (gray butyl stoppers; 20-mm diameter; 27232; SigmaAldrich Co.), and then incubated at $39^{\circ} \mathrm{C}$ in a shaking water bath (50 rpm). Blank samples (diluted rumen fluid only) and an internal standard (Gelose 80 maize starch; Penford Food Ingredients Co., Englewood, CO) were also included. After different incubation times, bottles were plunged into a bath containing ice to stop starch degradation. Residual starch was quantified using a 2-step enzymatic approach detailed previously (Gallo et al., 2016).

The IVSD after 7 or $120 \mathrm{~h}$ of rumen incubation was calculated as

$$
\begin{gathered}
\text { IVSD, \% starch }=[1-(\text { resStarch }- \text { blnStarch }) / \\
\text { incStarch }] \times 100 \%,
\end{gathered}
$$

where resStarch is the amount of residual starch after 7 or $120 \mathrm{~h}$ of rumen incubation; blnStarch is the blank 
Table 1. Mean values ${ }^{1}$ of starch content and mean particle size $\left(\mathrm{mPS}^{2}\right)$ of starch-based feed processed through 2 different grinding mills equipped without or with different screens

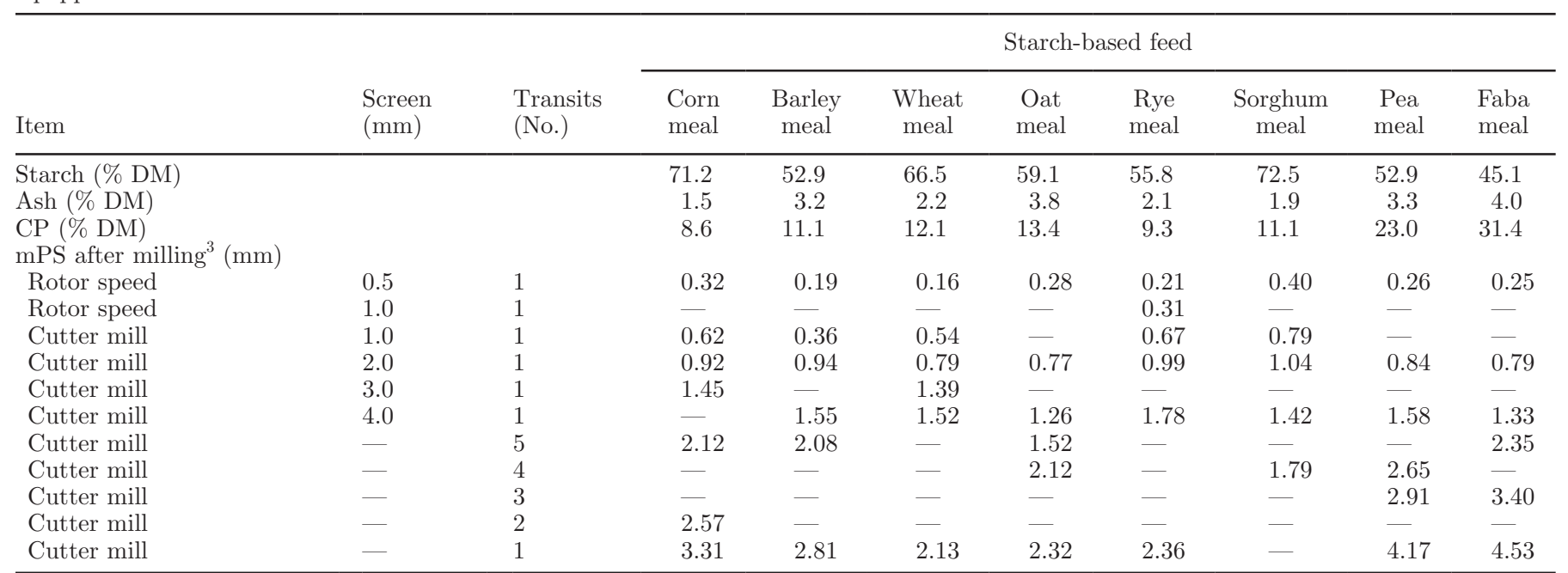

${ }^{1}$ Values are means of 2 replicates, 1 for each batch.

${ }^{2}$ Calculated using a sieve shaker (Multidimensional Sieveshaker IG/1/S, Giuliani Tecnologie s.r.l., Torino, Italy) equipped with screen sieves with nominal openings of 4.00, 3.50, 2.50, 1.50, 0.75, 0.50, 0.25, and $0.125 \mathrm{~mm}$, followed by a pan. The mPS was measured applying equation number 1 , as reported in the ASABE (2006), ASAE S319.3 method.

${ }^{3}$ Cutter mill Pulviresette 19 and rotor speed mill Pulverisette 14 (Fritsch, Idar-Oberstein, Germany).

correction at the corresponding incubation time; and incStarch is the amount of starch in the sample before incubation. The resStarch and blnStarch values were calculated from the glucose concentration and dilutions, and by converting free glucose to starch using a fixed factor of 0.9. All terms are expressed in grams and 3 bottles were used for each incubation time. The kd starch (per hour) was calculated from the IVSD data after $7 \mathrm{~h}$ of rumen incubation, using a first-order model with a fixed discrete lag time of $0.5 \mathrm{~h}$. A fixed indigestible starch fraction (iStarch) of $0.5 \%$ starch was used because the 120-h IVSD values were greater than 98 to 99\% starch in all analyzed samples. Thus, the kinetic model (Bender et al., 2016) was

$$
\mathrm{R}(t)=(100-\mathrm{iStarch}) \times\left[1-\mathrm{e}^{\mathrm{kd} \operatorname{starch} \times(t-\mathrm{Lag})}\right]
$$

where $\mathrm{R}(t)$ is the percentage of rumen starch degraded at time $t ; \mathrm{kd}$ starch is the kinetic constant of rumen starch degradation (per hour); $t$ is time (h); iStarch is the percentage of rumen indigestible starch; and Lag is the lag time $(0.5 \mathrm{~h})$.

To measure rumen fermentability (gas production; Menke and Steingass, 1988), samples were incubated in the same diluted rumen fluid (buffer-to-rumen ratio 2:1, $\mathrm{vol} / \mathrm{vol}$ ) used in the IVSD experiments. Briefly, about $220 \mathrm{mg}$ of each feed sample was weighed in graduated 100-mL glass gas-tight syringes equipped with a piston (Sigma-Aldrich Co.) and then $30 \mathrm{~mL}$ of diluted rumen fluid was added. Before injection into the syringes, the medium was saturated with $\mathrm{CO}_{2}$ and the $\mathrm{pH}$ corrected to 6.5 to 6.6. All gas was then expelled from the syringe, after which the lower end was closed. Syringes with samples, blanks, and an internal standard were placed vertically in a water bath at $39^{\circ} \mathrm{C}$, and gas production was measured at $1,2,4,6,8,12,24,48,72,96$, and $120 \mathrm{~h}$ of incubation. Syringes were manually agitated at every measurement.

The kinetics of gas production (kd) was computed by a single-pool exponential model (Wang et al., 2013):

$$
\mathrm{V}(t)=\mathrm{Vf} \times\left[1-\mathrm{e}^{-\mathrm{kd} \times(t-\mathrm{Lag})}\right],
$$

where $\mathrm{V}(t)$ is the volume of gas accumulated $(\mathrm{mL} / \mathrm{g}$ of $\mathrm{OM})$ at time $t$; $\mathrm{Vf}$ is the final gas volume $(\mathrm{mL} / \mathrm{g} \mathrm{OM})$; $\mathrm{kd}$ is the kinetic constant (per hour ); $t$ is time (h), and Lag is the lag time (h). For both in vitro tests, samples were incubated in triplicate in 2 separate runs. Samples within the run were considered analytical repetitions, and samples between runs as experimental replicates.

The IVSD data and kinetics of gas production were evaluated using a completely randomized design with the MIXED procedure of SAS Institute (2003). Each tested starch-based feed was separately analyzed using the model

$$
\mathrm{Y}_{\mathrm{ij}}=\mu+\mathrm{mPS}_{\mathrm{i}}+\mathrm{e}_{\mathrm{ij}},
$$

where $Y_{\mathrm{ij}}$ is the response variable; $\mu$ is the overall mean; $\mathrm{mPS}_{\mathrm{i}}$ is the fixed effect of mPS for a specific feed ( $\mathrm{i}=$ 
7 for corn meal, $\mathrm{i}=6$ for barley, wheat, oat, rye, pea, and faba meals, and $\mathrm{i}=5$ for sorghum meal); and $\mathrm{e}_{\mathrm{ij}}$ is the random residual error. The REG proc of SAS Institute (2003) was used for each specific feed to verify relationships between mPS (independent variable) and the parameters of interest (7hIVSD, kd starch, kd, and lag). Before regression analysis, all experimental replicates were averaged. A regression term (y-axis intercept, linear and quadratic terms) was considered significant at $P<0.05$. When the quadratic effect was not significant, it was removed by regression model.

Several feed evaluation systems (NRC, 2001; NorFor, 2011; Higgs et al., 2015) take into account the effect of $\mathrm{mPS}$ of meals entering into dairy cow diets to evaluate their energy content. However, the proposed adjustment factors are categorical, being related to feed categories or distinguishing meals into broad mPS classes (e.g., coarse-, medium-, or fine-ground feed grains). For instance, NRC (2001) used an empirical approach based on a processing adjustment factor to adapt the truly digestibility of the NFC fraction to the physical form of meals. The processing adjustment factor was 1.00 for ground corn, 0.95 for cracked dry corn, and 1.04 for all other cereal meals or rolled grains.

The adopted procedure of processing the different starch-based feeds led to a wide range in mPS (Table 1 ). In particular, the mPS of samples ranged from very small $\mathrm{mPS}$ values (i.e., $<0.40 \mathrm{~mm}$ ) to values greater than $2.00 \mathrm{~mm}$, except for sorghum meals (i.e., 1.79 $\mathrm{mm})$. The starch, ash, and CP of the starch-based feeds were in accordance with their expected chemical compositions and did not numerically differ among meals varying in mPS within the same starch-based feed.

Tables 2 and 3 shows the results of the IVSD and gas production experiments. Overall, the 7hIVSD and kd starch decreased $(P<0.05)$ as the mPS increased, in agreement with previous studies performed in vitro (Hoffman et al., 2012; Tagawa et al., 2017) and in vivo (San Emeterio et al., 2000; Callison et al., 2001). In particular, the 7hIVSD values decreased linearly with mPS $(P<0.05)$ in corn, barley, wheat, rye, pea, and faba feeds, and quadratically $(P<0.05)$ for the other feeds (Figure 1). The 7hIVSD y-axis intercepts were below $90 \%$ starch for corn, barley, and rye feeds, but greater than $90 \%$ starch for the other feeds. Analysis of the $\mathrm{kd}$ starch indicated linear decreases $(P<0.05)$ with mPS for barley, wheat, rye, and pea feeds, and quadratic decreases $(P<0.05)$ for the other feeds. Furthermore, the $\mathrm{y}$-axis intercepts were low for corn $(0.335$ $\left.\mathrm{h}^{-1}\right)$, barley $\left(0.289 \mathrm{~h}^{-1}\right)$, and rye $\left(0.296 \mathrm{~h}^{-1}\right)$; moderate for wheat $\left(0.394 \mathrm{~h}^{-1}\right)$ and faba $\left(0.399 \mathrm{~h}^{-1}\right)$; and high for oats $\left(0.458 \mathrm{~h}^{-1}\right)$, sorghum $\left(0.443 \mathrm{~h}^{-1}\right)$, and pea $(0.470$ $\left.\mathrm{h}^{-1}\right)$. Consequently, the mPS adjustment factors differed for the different feeds. The mPS can influence the surface area of the starch granules, and thereby affect bacterial attachment and starch degradation (Hoffman et al., 2012; Giuberti et al., 2014). Thus, the present findings can be explained as resulting from interactions of several physicochemical properties of the selected starch feeds. These include the chemical composition of the feed, starch granule morphology, amylose-to-amylopectin ratio, presence of a protein matrix encapsulating the starch granules, and adaptation of rumen bacteria to different starch sources (Svihus et al., 2005; Lanzas et al., 2007; Giuberti et al., 2014).

Some criticisms could be raised concerning the methods we used to calculate kd starch. In particular, the kd starch calculation was computed using 2 fixed points common to all tested starch meals $(0 \%$ starch or $99.5 \%$ starch for rumen incubations of 0 or $120 \mathrm{~h}$ ) and by adopting a fixed lag time of $0.5 \mathrm{~h}$. Consequently, the only factor determining rate was the 7hIVSD, thus representing the simplest approach to get a rate. However, the development of a starch degradability profile by adopting IVSD methods with a greater number of incubation times is difficult, as previously reported (Cone, 1991; Giuberti et al., 2014; Gallo et al., 2016). In particular, the IVSD assay is more labor-intensive and has lower reproducibility than other in vitro approaches. Thus, optimization of IVSD methods is a topic that needs further investigation.

The gas production technique has been widely used to evaluate the nutritive value of feeds (Getachew et al., 1998). In particular, gas production data, in combination with chemical analysis, can predict in vivo OM digestibility, ME, and rumen protein degradability of several feedstuffs. However, the use of gas production parameters often fails to properly explain the extent of degradation of specific nutrients in the rumen or animal performance, thus limiting its application in nutrition models (France et al., 2000; Chai et al., 2004; Lanzas et al., 2007). The kinetic parameters of current gas production data are in line with previous results (Gallo et al., 2016). In particular, we found a linear decrease in $\mathrm{kd}(P<0.05)$ with increasing mPS for each tested feed except for pea meals, which was better described by a quadratic fit $(P<0.05$; Figure 2$)$. The $\mathrm{y}$-intercepts for kd ranged between 0.047 (faba) and $0.078 \mathrm{~h}^{-1}$ (oat). For each 1-mm increase in mPS, the $\mathrm{kd}$ declined by $0.009 \mathrm{~h}^{-1}$ for corn, $0.011 \mathrm{~h}^{-1}$ for barley, $0.008 \mathrm{~h}^{-1}$ for wheat, and $0.006 \mathrm{~h}^{-1}$ for faba. Thus, the mPS adjustment factors for $\mathrm{kd}$ as a function of $\mathrm{mPS}$ were numerically different for oat $\left(-0.022 \mathrm{~h}^{-1}\right)$, rye $\left(-0.017 \mathrm{~h}^{-1}\right)$, and sorghum $\left(-0.014 \mathrm{~h}^{-1}\right)$. Furthermore, the lag increased linearly $(P<0.05)$ with increasing mPS for barley, wheat, oat, sorghum, and faba meals $(P<0.05)$ and quadratically for corn and pea $(P<$ $0.05)$. 


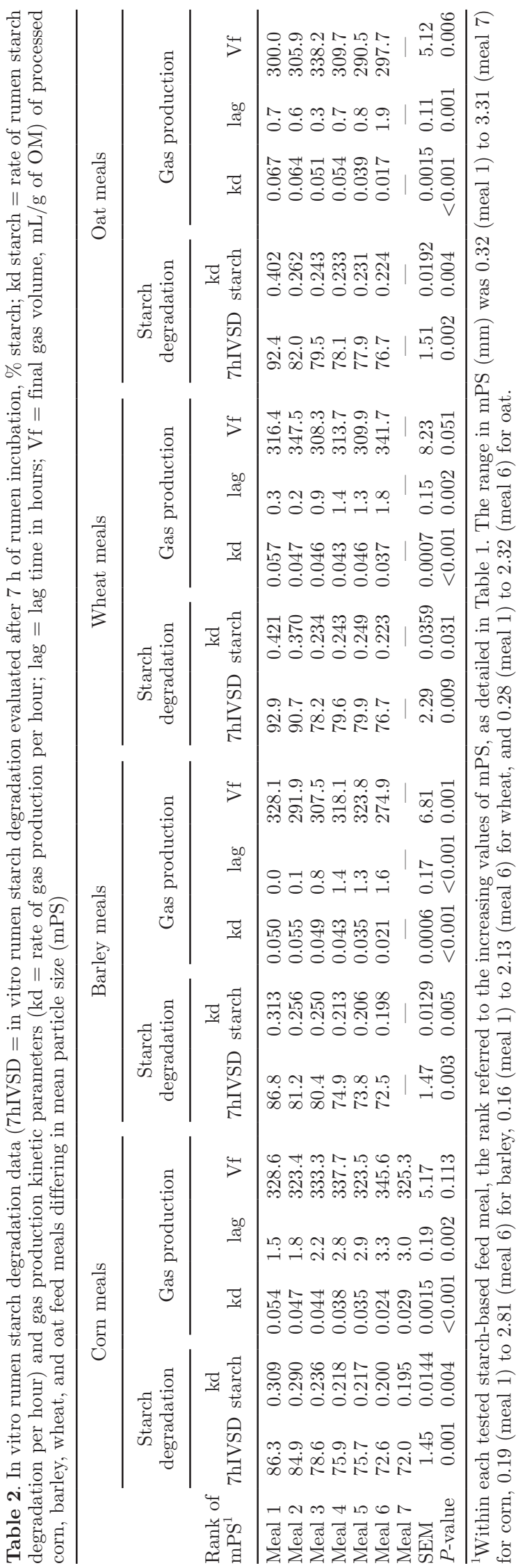

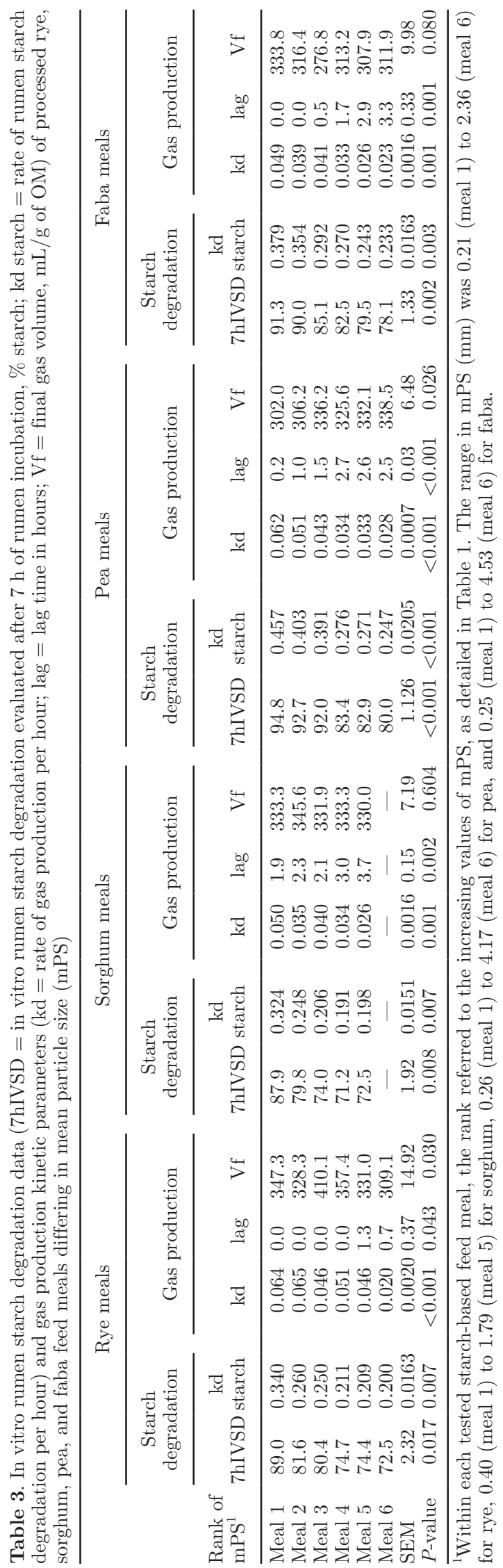


In the current study, we described gas production kinetics by fitting the data to a single pool exponential model. In a previous study (Gallo et al., 2016), we evaluated the opportunity to identify fast and slow pools by adopting a 2-pool exponential model and a Gompertz model. We did so in an attempt to improve the dynamic feed evaluation models by incorporating specific kd for fast and slow digestible pools of carbohy-
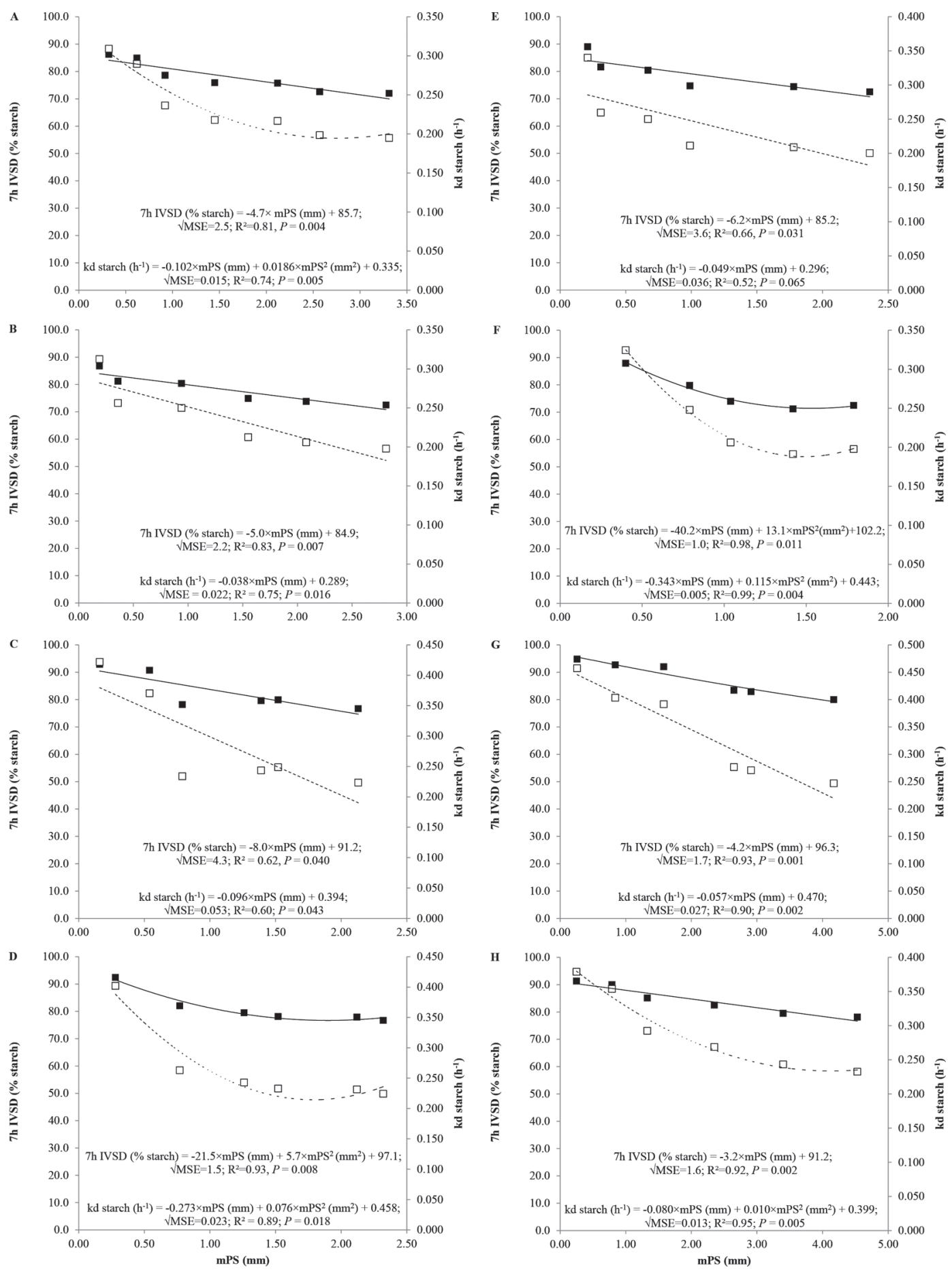

Figure 1. In vitro starch degradation data of corn (A), barley (B), wheat (C), oat (D), rye (E), sorghum (F), pea (G), and faba (H) meals differing in mean particle size (mPS). $7 \mathrm{~h}$ IVSD $=$ in vitro starch degradation evaluated after $7 \mathrm{~h}$ of rumen incubation; $\mathrm{kd}$ starch $=$ rate of starch degradation. Black or white squares refer to variables of interest displayed on left (primary) or right (secondary) sizes of Y-axes, respectively. $\mathrm{MSE}=$ mean squared error. 

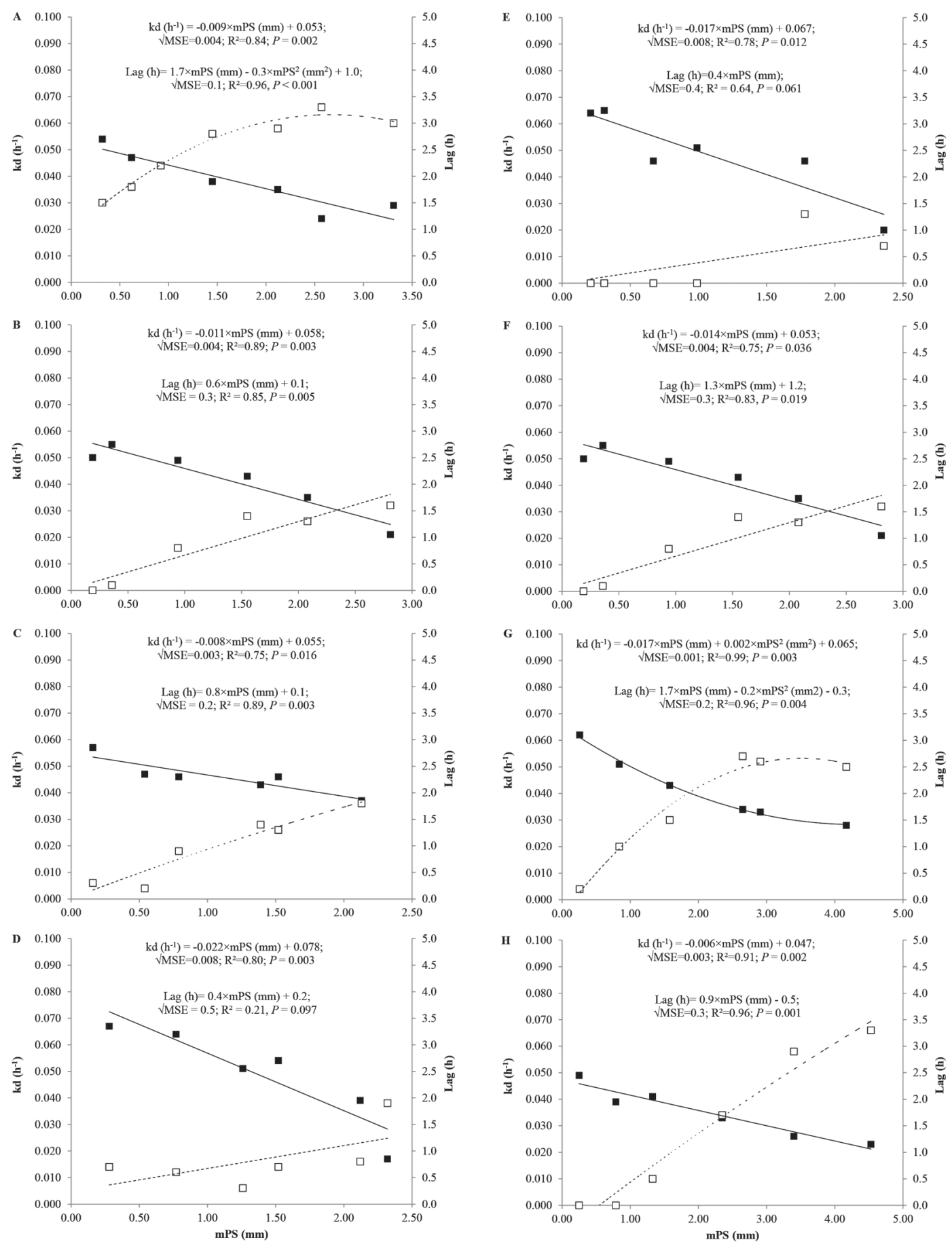

Figure 2. Fitted kinetic parameters of gas production of corn (A), barley (B), wheat (C), oat (D), rye (E), sorghum (F), pea (G), and faba $(\mathrm{H})$ meals differing in mean particle size $(\mathrm{mPS}) . \mathrm{kd}=$ rate of gas production; $\mathrm{Lag}=\mathrm{lag}$ time. Black or white squares refer to variables of interest displayed on left (primary) or right (secondary) sizes of Y-axes, respectively. MSE = mean squared error.

drate fractions (Zontini et al., 2015). The 2-pool exponential model provided inadequate characterization of the feeds, whereas the 2-pool sigmoidal model permitted identification of fast and slow digestible pools, but only in corn, barley, wheat, oat, and rye meals (data not shown).

In conclusion, the data from current in vitro experiments permitted us to model the effect of mPS on IVSD 
and the kinetics of gas production of diverse starchbased feeds. However, these results must be validated by controlled in vivo digestibility studies that evaluate the effect of different starch sources and particle sizes on starch digestion in the rumen.

\section{ACKNOWLEDGMENTS}

Special thanks to Marika Contesini, Federico Ferrari, and Silvia Ferrari for their support in the laboratory. This project was funded by the Fondazione Romeo ed Enrica Invernizzi (Milan, Italy) and by Servizio Sviluppo Sistema Agroalimentare of Regione Emilia-Romagna (Bologna, Italy; legge regionale 11 agosto 1998 n. 28 "Promozione dei Servizi di Sviluppo del Sistema Agro-Alimentare").

\section{REFERENCES}

AOAC International. 2000. Official Methods of Analysis, 17th ed. AOAC Int., Gaithersburg, MD.

ASABE (American Society of Agricultural and Biological Engineers). 2006. Methods of Determining and Expressing Fineness of Feed Materials by Sieving. ASAE S319.4. ASABE, St. Joseph, MI.

Bannink, A., H. J. van Lingen, J. L. Ellis, J. France, and J. Dijkstra. 2016. The contribution of mathematical modeling to understanding dynamic aspects of rumen metabolism. Front. Microbiol. $7: 1820$.

Bender, R. W., D. E. Cook, and D. K. Combs. 2016. Comparison of in situ versus in vitro methods of fiber digestion at 120 and 288 hours to quantify the indigestible neutral detergent fiber fraction of corn silage samples. J. Dairy Sci. 99:5394-5400.

Callison, S. L., J. L. Firkins, M. L. Eastridge, and B. L. Hull. 2001. Site of nutrient digestion by dairy cows fed corn of different particle sizes or steam-rolled. J. Dairy Sci. 84:1458-1467.

Chai, W. Z., A. H. van Gelder, and J. W. Cone. 2004. Relationship between gas production and starch degradation in feed samples. Anim. Feed Sci. Technol. 114:195-204.

Cone, J. W. 1991. Degradation of starch in feed concentrates by enzymes, rumen fluid and rumen enzymes. J. Sci. Food Agric. 54:23-34.

Ferraretto, L. F., P. M. Crump, and R. D. Shaver. 2013. Effect of cereal grain type and corn grain harvesting and processing methods on intake, digestion, and milk production by dairy cows through a meta-analysis. J. Dairy Sci. 96:533-550.

France, J., J. Dijkstra, M. S. Dhanoa, S. Lopez, and A. Bannink. 2000. Estimating the extent of degradation of ruminant feeds from a description of their gas production profiles observed in vitro: derivation of models and other mathematical considerations. Br. J. Nutr. 83:143-150.

Gallo, A., G. Giuberti, and F. Masoero. 2016. Gas production and starch degradability of corn and barley meals differing in mean particle size. J. Dairy Sci. 99:4347-4359.

Getachew, G., M. Blummel, H. P. S. Makkar, and K. Becker. 1998. In vitro gas measuring techniques for assessment of nutritional quality of feeds: a review. Anim. Feed Sci. Technol. 72:261-281.

Ghimire, S., R. A. Kohn, P. Gregorini, R. R. White, M. D. Hanigan, E. Schuller, and B. W. McBride. 2017. Representing interconversions among volatile fatty acids in the Molly cow model. J. Dairy Sci. 100:3658-3671.

Giuberti, G., A. Gallo, F. Masoero, L. F. Ferraretto, P. C. Hoffman, and R. D. Shaver. 2014. Factors affecting starch utilization in large animal food production system: A review. Starke 66:72-90.
Higgs, R. J., L. E. Chase, D. A. Ross, and M. E. Van Amburgh. 2015. Updating the Cornell Net Carbohydrate and Protein System feed library and analyzing model sensitivity to feed inputs. J. Dairy Sci. 98:6340-6360.

Hoffman, P. C., D. R. Mertens, J. Larson, W. K. Coblentz, and R. D. Shaver. 2012. A query for effective mean particle size in dry and high-moisture corns. J. Dairy Sci. 95:3467-3477.

Lanzas, C., D. G. Fox, and A. N. Pell. 2007. Digestion kinetics of dried cereal grains. Anim. Feed Sci. Technol. 136:265-280.

Menke, K. H., and H. Steingass. 1988. Estimation of the energetic feed value obtained from chemical analysis and gas production using rumen fluid. Anim. Res. Dev. 28:7-55.

Moharrery, A., M. Larsen, and M. R. Weisbjerg. 2014. Starch digestion in the rumen, small intestine, and hind gut of dairy cows - A meta-analysis. Anim. Feed Sci. Technol. 192:1-14.

NRC. 2001. Nutrient Requirements of Dairy Cattle. 7th rev. ed. Natl. Acad. Sci., Washington, DC.

Nocek, J. E., and S. Tamminga. 1991. Site of digestion of starch in the gastrointestinal tract of dairy cows and its effect on milk yield and composition. J. Dairy Sci. 74:3598-3629.

NorFor. 2011. NorFor-The Nordic Feed Evaluation System. 1st edition. Wageningen Academic Publishers, Wageningen, the Netherlands.

Offner, A., and D. Sauvant. 2004. Prediction of in vivo starch digestion in cattle from in situ data. Anim. Feed Sci. Technol. 111:41-56.

Patton, R. A., J. R. Patton, and S. E. Boucher. 2012. Defining ruminal and total-tract starch degradation for adult dairy cattle using in vivo data. J. Dairy Sci. 95:765-782.

Penner, G. B., J. R. Aschenbach, G. Gabel, R. Rackwitz, and M. Oba. 2009. Epithelial capacity for apical uptake of short chain fatty acids is a key determinant for intraruminal $\mathrm{pH}$ and the susceptibility to subacute ruminal acidosis in sheep. J. Nutr. 139:1714-1720.

Pfost, H., and V. Headley. 1976. Methods of determining and expressing particle size. Pages 512-520 in Feed Manufacturing Technology II. H. Pfost, ed. Am. Feed Manufacturers Assoc., Arlington, VA.

San Emeterio, F., R. B. Reis, W. E. Campos, and L. D. Satter. 2000. Effect of coarse or fine grinding on utilization of dry or ensiled corn by lactating dairy cows. J. Dairy Sci. 83:2839-2848.

SAS Institute. 2003. Guide for Personal Computers, Version 9.2. SAS Inst. Inc., Cary, NC.

Silveira, C., M. Oba, W. Z. Yang, and K. A. Beauchemin. 2007. Selection of barley grain affects ruminal fermentation, starch digestibility, and productivity of lactating dairy cows. J. Dairy Sci. 90:2860-2869.

Sveinbjörnsson, J., M. Murphy, and P. Udén. 2007. In vitro evaluation of starch degradation from feeds with or without various heat treatments. Anim. Feed Sci. Technol. 132:171-185.

Svihus, B., A. K. Uhlen, and O. M. Harstad. 2005. Effect of starch granule structure, associated components and processing on nutritive value of cereal starch: A review. Anim. Feed Sci. Technol. 122:303-320.

Tagawa, S. I., L. Holtshausen, T. A. McAllister, W. Z. Yang, and K. A. Beauchemin. 2017. Effects of particle size of processed barley grain, enzyme addition and microwave treatment on in vitro disappearance and gas production for feedlot cattle. Asian-Australas. J. Anim. Sci. 30:479-485.

Wang, M., X. Z. Sun, S. X. Tang, Z. L. Tan, and D. Pacheco. 2013. Deriving fractional rate of degradation of logistic-exponential (LE) model to evaluate early in vitro fermentation. Animal 7:920-929.

Zhao, Y. L., S. M. Yan, Z. X. He, U. Y. Anele, M. L. Swift, T. A. McAllister, and W. Z. Yang. 2015. Effects of volume weight, processing method and processing index of barley grain on in situ digestibility of dry matter and starch in beef heifers. Anim. Feed Sci. Technol. 199:93-103.

Zontini, A., A. Foskolos, D. A. Ross, J. Metcalf, P. H. Doane, and M. E. Van Amburgh. 2015. Research update: formulating diets for lactating cattle using multiple pools of NDF digestibility. Pages 189-196 in Cornell Nutrition Conference Proceedings, East Syracuse, NY. 